\title{
Clinical Complications of
} Hemoglobinopathies in Western Saudi Arabia and the Need for Specialized Care Centers

\author{
Maha A. Badawi, FRCPC, DRCPSC, Soheir S. Adam, FRCPath, \\ Abdulrahman H. Ghoneim, MBBS, Ahmed A. Jamjoom, MBBS, \\ Ahmed N. Sahly, MBBS, Thunayyan M. Almasoudi, MBBS, \\ Galila F. Zaher, DipRCPath, FRCPath, and Salwa I. Hindawi, CTM, FRCPath \\ Department of Hematology, Faculty of Medicine, King Abdulaziz University \\ Jeddah, Saudi Arabia
}

\section{Correspondence}

Dr. Maha A. Badawi

Department of Hematology

Faculty of Medicine, King Abdulaziz University

P.O. Box 80215, Jeddah 21589

Saudi Arabia

e.M: mbadawi2@kau.edu.sa

\section{Submission: 21 Nov, 2018 \\ Accepted: $\quad 02$ Feb. 2019}

\section{Citation}

Badawai MA, Adam SS, Ghoneim AH, Jamjoom AA, Sahly AN, Almasoudi TM, Zaher GF, Hindawi SI. Clinical complications of hemoglobinopathies in Western Saudi Arabia and the need for specialized care centers. JKAU Med Sci 2019; 26 (1): 29-36. DOl: 10.4197/Med. 26-1.5

Copyright: (T) The Author(s), YEAR. Publisher. The Journal of King Abdualziz University - Medical Sciences is an Official Publication of "King Abdulaziz University". It is an open-access article distributed under the terms of the Creative Commons Attribution Non-Commercial License, which permit unrestricted non-commercial use, distribution, and reproduction in any medium, provided the original work is properly cited.

\begin{abstract}
In the absence of specialized care centers for hemoglobinopathies in Saudi Arabia, there are insufficient data on prevalence of clinical complications in this population. This is a retrospective record review about the clinical complications associated with hemoglobinopathies at King Abdulaziz University Hospital, for patients followed between January 1st 2010 through June 30th 2016. A total of 349 patients were included, with a mean age of 25.45 years, including 266 with sickle cell disease and 80 with thalassemia. Of those receiving regular transfusions, $17.5 \%$ developed alloantibodies, $16.6 \%$ tested positive for hepatitis C virus antibodies and the mean ferritin level was 2487 $\mathrm{ng} / \mathrm{ml}$. Almost half of the patients were screened for renal disease, and more than $50 \%$ were found to have proteinuria. Of 203 patients with recent echocardiograms, $15.8 \%$ had pulmonary hypertension. Thirty-one (8.9\%) patients died at a mean age of 28.5 years. In conclusion, the prevalence of disease related complications is high in hemoglobinopathies. Our results reiterate the need for specialized care hemoglobinopathy centers, which can further improve patient outcomes.
\end{abstract}

\section{Keywords}

Sickle cell disease; Thalassemia; Specialized hemoglobinopathy center

\section{Introduction}

halassemia and sickle cell disease (SCD) are two of the most common inherited genetic disorders worldwide. It is estimated that $7 \%$ of the world population are carriers for hemoglobinopathies ${ }^{[1]}$ and 300,000-500,000 children are born annually with hemoglobin disorders ${ }^{[2]}$.
The global mortality rate for hemoglobin disorders is $3.4 \%$ in children less than 5 years ${ }^{[3]}$. Thalassemia and SCD can affect all organs, thus patients with these chronic conditions typically utilize a sizable fraction of health care resources and associated costs ${ }^{[4-6]}$. Improving morbidity and mortality in these patients is an urgent global need ${ }^{[7]}$. 
Treatment modalities for SCD and thalassemia are limited. Hydroxyurea and L-Glutamine are the two FDA-approved drugs for management of $\mathrm{SCD}^{[8]}$, and transfusion is life-saving in certain clinical complications associated with the disease $\mathrm{e}^{[9]}$. Transfusion is the mainstay of management of thalassemia. However, transfusion-associated complications, including alloimmunization and iron overload represent an ongoing challenge ${ }^{[10,11]}$. Furthermore, untreated iron overload is associated with risk of endocrine failure, cardiomyopathy, liver cirrhosis, hepatobilliary cancer, and early death ${ }^{[12-14]}$.

In Saudi Arabia, the prevalence of SCD is up to $2.7 \%$, and that of sickle cell trait ranges between $2 \%$ and $27 \%{ }^{[15]}$. The total annual incidence of symptomatic individuals with $\beta$-thalassemia in Saudi Arabia is 0.5 per 1000 , and 18.0 per 1000 for carriers ${ }^{[16]}$. Thus, hemoglobinopathies represent a significant health care burden and long-term outcomes are largely dependent on future advances in comprehensive care. Given that there are limited local and regional data on the complications and clinical outcomes of hemoglobinopathies, we report on the characteristics and clinical complications of this cohort of patients receiving care at King Abdulaziz University Hospital $(\mathrm{KAUH})$, a tertiary academic medical center in Jeddah, Saudi Arabia.

\section{Methods}

King Abdulaziz University Hospital is an academic hospital with a capacity of around 600 beds. Patients with hemoglobinopathies are referred from the Makkah region and other regions within the Kingdom. In our hematology laboratory, patients with suspected hemoglobinopathies undergo routine evaluation using Sebia capillary electrophoresis instruments (Sebia, Evry Cedex, France) a method that is recognized to provide comparable results with cellulose acetate electrophoresis ${ }^{[17]}$.

In this study, patients were eligible for inclusion if they were diagnosed with a hemoglobinopathy based on capillary hemoglobin electrophoresis and were followed up at KAUH from the $1^{\text {st }}$ of January 2010 to the $30^{\text {th }}$ of June 2016. Approval to conduct this study was obtained from KAU Research Ethics Committee, and the study was performed in accordance with the ethical standards outlined in the 1964 Declaration of Helsinki and its later amendments. Medical record numbers were retrieved through the hospital information system using relevant International Classification of Diseases- 10 codes. Using a standardized data extraction sheet, we reviewed patients' electronic and paper records. For details on pre-transfusion compatibility testing and antibody identification results, records from blood transfusion service were reviewed. Patients were excluded if an objective diagnosis was missing.

\section{Data Collection}

The following information was collected; 1) General demographics including; age, gender and nationality, 2) Relevant laboratory values, 3) Markers of end organ damage, 4) Details of hospital admissions, and 5) Transfusion history including alloantibody screening and identification, transfusion reactions and transfusion transmitted infections.

Hematological indices were expressed as the mean of the three most recent values obtained in the outpatient clinic including; hemoglobin level $(\mathrm{Hb})$, hematocrit, platelet count, white blood cells count and absolute neutrophil count. Laboratory markers of hemolysis were recorded including absolute reticulocyte counts, and lactate dehydrogenase. Data reflecting end organ damage included; ferritin as a marker of iron overload, liver function, renal function, proteinuria, and pulmonary hypertension as measured by tricuspid regurgitation $\geq 2.5 \mathrm{~m} / \mathrm{second}$ on echocardiogram examination. Unfortunately, the results of transverse relaxation time weighted magnetic resonance imaging (MRI T2*) studies were not accessible at the time of the analysis and therefore the related information could not be collected. Current medications, hypertension, history of stroke, history of splenectomy, history of venous thromboembolism and hospital admissions during the previous year were also recorded. Further, data on disease-specific complications such as acute chest syndrome in sickle cell disease were included.

\section{Statistical Methodology}

This study was analyzed using IBM SPSS Statistics for Windows, Version 20 (IBM Corp., Armonk, NY USA). A simple descriptive statistic was used to define the characteristics of the study variables through a form of counts and percentages for the categorical and nominal variables while continuous variables are presented by mean and standard deviations. 


\section{Results}

\section{Demographics of Patient Population}

Three hundred and forty-nine patients with a mean age of 25.45 years $( \pm 9.068)$ were included in the study. Of these, 185 (53\%) were males and 131 (37.6\%) were Saudi nationals. The remaining patients were born in 15 different countries (including Arab, African, and Asian countries). There were 266 (76.2\%) SCD patients, $80(22.9 \%)$ patients with beta-thalassemia major, and three with hemoglobin E disease. Details on characteristics of SCD and thalassemia patients are reported separately elsewhere.

\section{Evidence of End Organ Damage}

Mean ferritin level, a marker of iron overload was 2487.94 $\mathrm{ng} / \mathrm{ml}$ ( \pm 34988) (Table 1). Recent echocardiogram results (within 12 months) were available for 203 patients and showed a mean ejection fraction of $63.69 \%$ ( \pm 8.4 ). Tricuspid regurgitation velocity of $\geq$ $2.5 \mathrm{~m} / \mathrm{second}$, reflecting pulmonary hypertension was present in 32 (15.8\%) out of 203 patients. Among the 198 patients who were screened for proteinuria, 102 (51.5\%) tested positive. Blood counts, liver enzymes, and renal functions are shown in Table 1.

\section{Viral Infections}

Forty-six (16.6\%) patients out of 277 tested positive for Hepatitis C Virus (HCV) antibodies, and two out of 270 screened patients were found to be positive for $\mathrm{HBsAg}$. All 196 patients screened for human immunodeficiency virus (HIV) antibody were negative.

None of the cases with positive testing for transfusion-transmitted infections (TTI) developed seroconversion while being treated within our center, and all presented with positive testing at time of initiation of care at KAUH.

\section{Other Clinical Complications}

Thirteen of the included patients (11 patients with SCD and 2 with thalassemia) experienced venous thrombotic events (7 deep venous thrombosis, 5 pulmonary emboli), and 46 (13.2\%) patients underwent splenectomy, while 20 (5.7\%) had cholecystectomy. Fourteen patients with SCD developed acute chest syndrome during the course of the disease. This is equal to $4.8 \%$ of the total number of SCD patients in this cohort. Out of 273 patients, 137 (50.2\%) were admitted to KAUH once within the preceding 12 months, while $67(24.5 \%)$ were admitted twice. The remaining 69

Table 1. Characteristics of study population.

\begin{tabular}{|c|c|c|c|c|}
\hline Demographics & $\mathbf{N}$ & Mean & SD & Reference Range at our Center \\
\hline Age & 349 & 25.45 & 9.07 & \\
\hline \multicolumn{5}{|l|}{ Clinical Data } \\
\hline Hemoglobin (g/dl) & 349 & 8.18 & 1.4 & $12-15$ \\
\hline Platelets (x109/L) & 349 & 446.56 & 223.4 & $150-450$ \\
\hline White blood cell count (x109/L) & 349 & 16.44 & 25.1 & $4.5-11.5$ \\
\hline Absolute reticulocyte count (x109/L) & 349 & 93 & 108 & $25-75$ \\
\hline Ferritin (ng/ml) & 295 & 2487.94 & 3488.7 & $13-150$ \\
\hline Creatinine (umol/L) & 339 & 60.18 & 72.6 & $53-115$ \\
\hline Lactate dehydrogenase (units/L) & 132 & 546.68 & 477 & $5100-249$ \\
\hline Aspartate aminotransferase (units/L) & 339 & 64.43 & 81.3 & $15-37$ \\
\hline Alanine aminotransferase (units/L) & 341 & 53.51 & 49.0 & $12-78$ \\
\hline Gamma glutamyl transferase (units/L) & 339 & 55.56 & 72.0 & $5-85$ \\
\hline Direct bilirubin (umol/L) & 275 & 17.17 & 41.4 & $0-5$ \\
\hline Prothrombin time (seconds) & 314 & 14.67 & 5.8 & $9.4-12.5$ \\
\hline Partial thromboplastin time (seconds) & 313 & 38.40 & 134.2 & $25-36.5$ \\
\hline$D$ dimer $(\mathrm{mg} / \mathrm{L})$ & 309 & 159.15 & 298.6 & $0-0.5$ \\
\hline C reactive protein (mg/L) & 325 & 19.34 & 40.0 & $0-3$ \\
\hline Systolic blood pressure (mmHg) & 117 & 111.50 & 11.4 & \\
\hline Diastolic blood pressure $(\mathrm{mmHg})$ & 117 & 64.64 & 9.8 & \\
\hline Heart rate (beats per minute) & 116 & 83.71 & 11.9 & $60-100$ \\
\hline Ejection fraction (\%) & 182 & 47.33 & 27.7 & \\
\hline Hospital admissions within past 12 months & 200 & 1.44 & 1.8 & \\
\hline
\end{tabular}


(25.3\%) were admitted more than two times, including planned admissions for regular blood transfusions.

\section{Mortality}

Thirty-one (8.9\%) patients died at a mean age of 28.46 $( \pm 11.2 \%)$ years. Unfortunately, no further details on causes of death were collected for this study purpose. However, it is considered for future cohort study.

\section{Medications}

Data on current medications were available for 345 patients. Of these, 73 (21.2\%) were on hydroxyurea, with a mean dose of $590 \mathrm{mg}$ (range 250-1500). Thirty-nine (11.2\%) patients were on anti-hypertensive treatment and 15 (4.3\%) received anti-epileptic medications. Data about utilization of iron chelation therapy could not be collected accurately from the electronic medical record.

\section{Transfusion and Alloimmunization Data}

Most of the patient population were group O (47.7\%), followed by group A (31.1\%). Sixty-one (17.5\%) patients developed antibodies against red cell antigens at a mean age of 18 years. The most common alloantibody identified in isolation was anti-E. Patients received a mean of 16 packed red cell transfusions per patient $\pm 22.4)$ before developing alloantibodies. No allergic reactions were reported and only one febrile reaction was documented.

\section{Discussion}

The prevalence of SCD in Saudi Arabia is variable in different geographical regions ${ }^{[15,16]}$. Results of the mandatory Saudi Premarital Screening Program (SPSP) show that the $0.26 \%$ of applicants had SCD, $4.2 \%$ had sickle cell trait (SCT), 3.22\% had thalassemia trait, while $0.07 \%$ had thalassemia disease ${ }^{[18]}$. Similar rates were seen six years following initiation of the SPSP ${ }^{[16]}$. A crosssectional community-wide survey targeting children and adolescents revealed that the rate of SCD was 24 in $100,000^{[19]}$. The prevalence of alpha-thalassemia gene is also high, ranging between $30-50 \%$ in various reports ${ }^{[20]}$.

Hemoglobinopathy patients are at risk for end organ damage, either secondary to the disease itself or secondary to chronic blood transfusion. The mean ferritin level in our study is over $2000 \mathrm{ng} / \mathrm{ml}$ reflecting iron overload. For many years, desferrioxamine was the solely used iron chelating agent in our center ${ }^{[21]}$. Since the introduction of deferasirox and deferiprone, more patients have been prescribed these oral agents to improve compliance. Since complications of iron overload constitute major causes of death in these patients, major efforts are necessary to enhance this aspect of their care. Having access to specialized care centers would allow coordinated follow up with a multi-disciplinary team, including a clinical pharmacist, patient educators, social workers, nurses and physicians from various subspecialties. Proper imaging techniques for evaluation of iron loading (such as MRI T2*) would also be accessible to these patients in a timely manner.

In a similar manner, specialized care centers are expected to improve rates of screening and management for other complications of hemoglobinopathies. This can be achieved through regular follow up by trained coordinators, or through an electronic support system. This would be valuable in such a cohort, as rates of screening with echocardiograms and proteinuria assessment in our patients were less than $60 \%$, despite that these tests are recommended by leading organizations ${ }^{[22,23]}$. The same applies to screening for TTI, as some patients in our cohort never underwent such testing.

Although the prevalence of hepatitis $C$ antibodies in our cohort $(16.6 \%)$ is higher than reported from a group of thalassemia patients in Al Hofuf (12.7\%) $)^{[24]}$, it is significantly lower than many reports covering the period from 1980 to $2000^{[25]}$. This may be explained by the improvement in blood donor selection and screening, resulting in a safer blood supply around the world.

Ensuring safety of blood is an integral part of the comprehensive management of hemoglobinopathies. Although transfusion services in Saudi Arabia are fragmented, regulatory authorities hold transfusion services in the Kingdom to high standards. Transfusion safety has been notably improved with the advent of mandatory nucleic acid testing for hepatitis $B$ virus $(\mathrm{HBV}), \mathrm{HCV}$, and HIV. Given that patients may receive transfusions in different hospitals during the course of their disease, and in the absence of a national database for patients with hemoglobinopathies on regular transfusion, it is difficult to determine whether HCV seroconversion occurred before or after introduction of nucleic acid testing on a national level. In fact, patients with hemoglobinopathies constitute the largest 
fraction of patients with HCV who have an identifiable risk factor in our institution ${ }^{[26]}$

Overall these findings highlight the need for better compliance without patient visits and more rigorous screening to allow early referrals to specialists, early initiation of therapy, and identification of associated risk factors.

A number of factors contribute to the gap in the comprehensive care of hemoglobinopathy patients. These include limited awareness of patients and caregivers, lack of psychosocial support, and the absence of a functional primary care model. This results in difficulties in accessing care from a multidisciplinary team. Poor adherence of patients to outpatient follow up appointments contributes to interruption of care. In addition, when treated in the same institution, patients with malignant diseases may be prioritized when resources (including appointments and beds) are allocated, in comparison with those suffering from conditions perceived as "benign".

To reduce inconsistency of care, specialized hemoglobinopathy centers should be established. Previously, access to such centers was found to be associated with better survival in thalassemia patients ${ }^{[27]}$, and improved compliance and quality indicators in SCD patients ${ }^{[28]}$. Specialized hemoglobinopathy centers provide comprehensive, coordinated, patientcentered care and allow smooth transition from pediatric to adult care. Furthermore, specialized staff members provide support to patients and families by addressing psychological and social needs. When compared with an "episodic" model of care, enrollment of SCD patients in comprehensive care programs was found to reduce cost, utilization of emergency department, length of hospitalization, and rate of readmission ${ }^{[28,29]}$. Quality of life outcomes were found to be poor in hemoglobinopathy patients compared to the general population ${ }^{[30-32]}$. Comprehensive care of hemoglobinopathies at specialized centers improves quality of life outcomes ${ }^{[33]}$, and leads to higher patient satisfaction ${ }^{[34]}$. Furthermore, early diagnosis and implementation of preventative care at specialized hemoglobinopathy centers reduces early mortality ${ }^{[35]}$.

Our data summarize some of the important clinical characteristics of patients with hemoglobinopathies in Western Saudi Arabia. Limitations of this study include some missing clinical data such as adherence to recommendations regarding vaccinations, periodic testing for TTI, and unavailability of accurate data about iron chelation and radiologic evaluation for iron loading. Mortality data are limited and do not allow for a meaningful comparison with the available literature. Nonetheless, the available findings identify opportunities for improvement of care provided to patients with hemoglobinopathies, such as providing psychosocial support and education of patients and families. Comprehensive hemoglobinopathy centers can provide support and consistent care of these chronic disorders. Furthermore, establishing a national registry of hemoglobinopathy patients would help characterize clinical outcomes of hemoglobinopathies in Saudi Arabia.

\section{Conclusions}

Patients with hemoglobinopathies should receive comprehensive patient-centered care including regular screening for organ dysfunction. Further efforts are required to implement prophylactic measures in early childhood and careful long-term follow-up in this population. Development of comprehensive hemoglobinopathy centers is encouraged to overcome inconsistencies in healthcare and provide necessary support to patients.

\section{Conflicts of Interest}

The authors declare no conflict of interest.

\section{Disclosure}

This project was funded by the Deanship of Scientific Research in King Abdulaziz University, Jeddah, under grant No. (G 202/248/1436).

\section{Ethical Approval}

Obtained.

\section{Acknowledgment}

The authors thank Dr. Anoud R. Omer for editorial assistance.

\section{References}

[1] Weatherall DJ. Hemoglobinopathies worldwide: present and future. Cur Mol Med 2008; 8(7): 592-599.

[2] [No authors listed]. WHO/TIF Meeting on the Management of Haemoglobin Disorders (2007: Nicosia, Cyprus) World Health Organization \& Thalassaemia International Federation. (2008) Management of haemoglobin disorders: 
report of a joint WHO-TIF meeting, Nicosia, Cyprus, 16-18 November 2007. Accessed on April 27, 2019. <https:// apps.who.int/iris/handle/10665/43969>.

[3] Modell B. Darlision M. Global epidemiology of haemoglobin disorders and derived service indicators. Bull World Health Organ 2008; 86(6): 480-487.

[4] Pizzo E, Laverty AA, Phekoo KJ, AlJuburi G, Green SA, Bell D, Majeed A. A retrospective analysis of the cost of hospitalizations for sickle cell disease with crisis in England, 2010/11. J Public Health (Oxf) 2015; 37(3): 529-539.

[5] Ngolet L, Moyen Engoba M, Kocko I, Elira Dokekias A, Mombouli JV, Moyen GM. Sickle-cell disease healthcare cost in Africa: Experience of the Congo. Anemia 2016; 2016: 2046535.

[6] Kauf TL, Coates TD, Huazhi L, Mody-Patel N, Hartzema AG. The cost of health care for children and adults with sickle cell disease. Am J Hematol 2009; 84(6): 323-327.

[7] Weatherall DJ. The inherited diseases of hemoglobin are an emerging global health burden. Blood 2010; 115(22): 4331-4336.

[8] Meier ER. Treatment options for sickle cell disease. Pediatr Clin North Am 2018; 65(3): 427-443.

[9] Telen MJ. Principles and problems of transfusion in sickle cell disease. Semin Hematol 2001; 38(4): 315-323.

[10] Higgs DR, Engel JD, Stamatoyannopoulos G. Thalassaemia. Lancet 2012; 379(9813): 373-383.

[11] Rachmilewitz EA, Giardina PJ. How I treat thalassemia. Blood 2011; 118(13): 3479-3488.

[12] Coates TD. Physiology and pathophysiology of iron in hemoglobin-associated diseases. Free Radic Biol Med 2014; 72: 23-40.

[13] Propper RD, Cooper B, Rufo R, Nienhuis AW, Anderson WF, Bunn HF, Rosenthal A, Nathan DG. Continuous subcutaneous administration of deferoxamine in patients with iron overload. N Engl J Med 1977; 297(8): 418-423.

[14] Coates TD, Carson S, Wood JC, Berdoukas V. Management of iron overload in hemoglobinopathies: what is the appropriate target iron level? Ann N Y Acad Sci 2016; 1368(1): 95-106.

[15] Jastaniah W. Epidemiology of sickle cell disease in Saudi Arabia. Ann Saudi Med 2011; 31(3): 289-293.

[16] Memish ZA, Owaidah TM, Saeedi MY. Marked regional variations in the prevalence of sickle cell disease and $\beta$-thalassemia in Saudi Arabia: findings from the premarital screening and genetic counseling program. J Epidemiol Glob Health 2011; 1(1): 61-68.

[17] Kim JE, Kim BR, Woo KS, Kim JM, Park JI, Han JY. Comparison of capillary electrophoresis with cellulose acetate electrophoresis for the screening of hemoglobinopathies. Korean J Lab Med 2011; 31(4): 238.
[18] AlHamdan NA, AlMazrou YY, AlSwaidi FM, Choudhry AJ. Premarital screening for thalassemia and sickle cell disease in Saudi Arabia. Genet Med 2007; 9(6): 372-377.

[19] Al-Qurashi MM, El-Mouzan MI, Al-Herbish AS, Al-Salloum AA, Al-Omar AA. The prevalence of sickle cell disease in Saudi children and adolescents. A community-based survey. Saudi Med J 2008; 29(10): 1480-1483.

[20] Al-Awamy BH. Thalassemia syndromes in Saudi Arabia. Meta-analysis of local studies. Saudi Med J 2000; 21(1): 8-17.

[21] Al Jaouni S. Survival and disease complication of thalassemia major: experience of 14 years at King Abdulaziz University Hospital, Jeddah, KSA. J KAU Med Sci 2010; 17(1): 19-28.

[22] Yawn BP, Buchanan GR, Afenyi-Annan AN, Ballas SK, Hassell

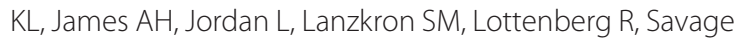
WJ, Tanabe PJ, Ware RE, Murad MH, Goldsmith JC, Ortiz E, Fulwood R, Horton A, John-Sowah J. Management of sickle cell disease: summary of the 2014 evidence-based report by expert panel members. JAMA 2014; 312(10): 10331048.

[23] Langhi D Jr, Ubiali EM, Marques JF Jr, Verissimo MA, Loggetto SR, Silvinato A, Bernardo WM. Guidelines on Betathalassemia major - regular blood transfusion therapy: Associação Brasileira de Hematologia, Hemoterapia e Terapia Celular: project guidelines: Associação Médica Brasileira - 2016. Rev Bras Hematol Hemoter 2016; 38(4): 341-345.

[24] Al Bahrani A, Panhotra BR. Prevalence of hepatitis C virus antibody in polytransfused $\beta$-thalassemia major patients. Ann Saudi Med 2002; 22(3-4): 270-272.

[25] Lai ME, Origa R, Danjou F, Leoni GB, Vacquer S, Anni F, Corrias C, Farci P, Congiu G, Galanello R. Natural history of hepatitis $C$ in thalassemia major: a long-term prospective study. Eur J Haematol 2013; 90(6): 501-507.

[26] Akbar HO, Al Ghamdi A, Qattan F, Fallatah HI, Al Rumani M. Chronic hepatitis $C$ in Saudi Arabia: three years local experience in a university hospital. Hepat Mon 2012; 12(9): e6178.

[27] Forni GL, Puntoni M, Boeri E, Terenzani L, Balocco M. The influence of treatment in specialized centers on survival of patients with thalassemia major. Am J Hematol 2009; 84(5): 317-318.

[28] Andemariam B, Jones S. Development of a new adult sickle cell disease center within an academic cancer center: impact on hospital utilization patterns and care quality. J Racial Ethn Health Disparities 2015; 3(1): 176-182.

[29] Yang YM, Shah AK, Watson M, Mankad VN. Comparison of costs to the health sector of comprehensive and episodic health care for sickle cell disease patients. Public Health Rep 1995; 110(1): 80-86.

[30] Ayoub MD, Radi SA, Azab AM, Abulaban AA, Balkhoyor AH, Bedair SW, Aljaouni SK, Kari JA. Quality of life among 
children with beta-thalassemia major treated in Western Saudi Arabia. Saudi Med J 2013; 34(12): 1281-1286.

[31] Ahmed AE, Alaskar AS, Al-Suliman AM, Jazieh AR, McClish DK, Al Salamah M, Ali YZ, Malhan H, Mendoza MA, Gorashi AO, El-Toum ME, El-Toum WE. Health-related quality of life in patients with sickle cell disease in Saudi Arabia. Health Qual Life Outcomes 2015; 13(1): 183.

[32] Beverung LM, Bemrich-Stolz C, Torres S, Panepinto JA. Health-related quality of life in infants with sickle cell disease. J Pediatr Hematol Oncol 2015; 37(8): 590-594.

[33] Ali SS, Tarawah AM, Al-Hawsawi ZM, Zolaly MA, Turkustani $W$. Comprehensive patient care improves quality of life in transfusion dependent patients with $\beta$-thalassemia. Saudi Med J 2015; 36(5): 575-579.

[34] Aisiku IP, Penberthy LT, Smith WR, Bovbjerg VE, McClish DK, Levenson JL, Roberts JD, Roseff SD. Patient satisfaction in specialized versus nonspecialized adult sickle cell care centers: the PiSCES study. J Natl Med Assoc 2007; 99(8): 886-890.

[35] King LG, Bortolusso-Ali S, Cunningham-Myrie CA, Reid ME. Impact of a Comprehensive Sickle Cell Center on early childhood mortality in a developing country: the Jamaican experience. J Pediatr 2015; 167(3): 702-705.e1. 


\section{المضاعفات الاكلينيكية لاى مرضى الأنيميا المنجلية والثُلاسيميا بالمنطقة الغربية

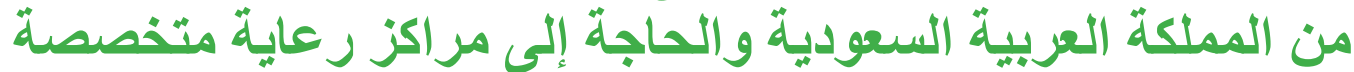

\section{مها عبد الرزاق بدوي و سهير سعيد آدم و عبد الرحمن حسام الاين غنيم و أحمد عاصم جمجوم و أحمد

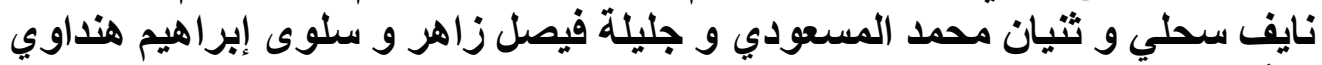

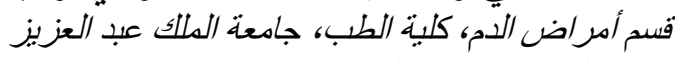

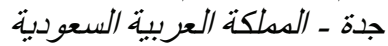

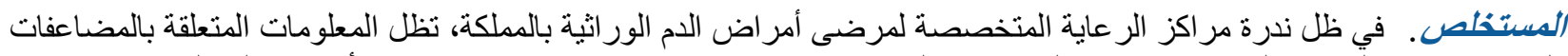

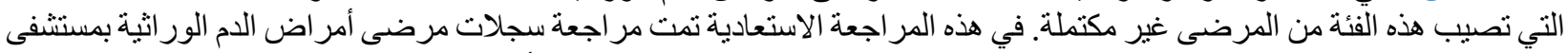

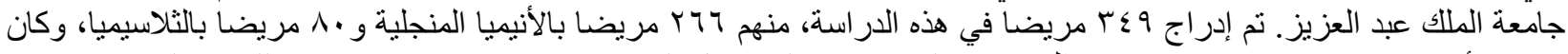

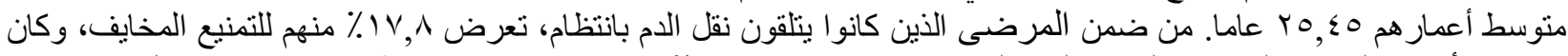

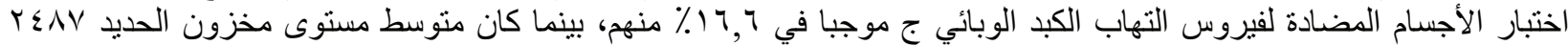

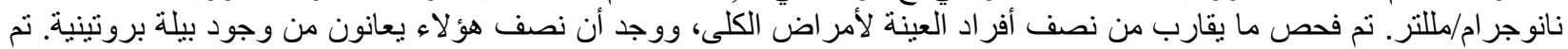

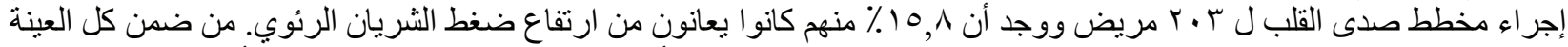

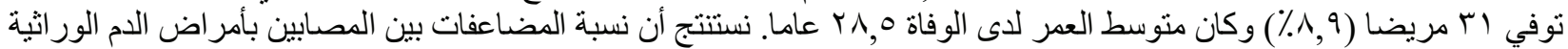

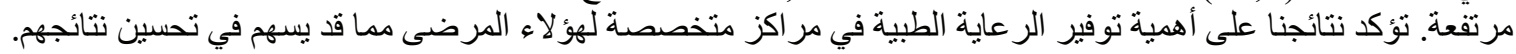

